\author{
Аймухамбетов T.T. ${ }^{\prime}$, Нуров М.M. ${ }^{l}$, Ержанова А.H. ${ }^{l}$ \\ ${ }^{1}$ Евразийский Национальный Университет имени Л.Н. Гумилева \\ ${ }^{2}$ Казахский национальный педагогический университет им. Абая
}

ФАКТОР НЕФОРМАЛЬНОЙ РЕЛИГИОЗНОСТИ МОЛОДЕЖИ

\begin{abstract}
Аннотащия
В статье обобщаются результаты эмпирического социологического исследования религиозности молодежи с субъективно-оценочных позиций.

На материалах исследования выявлены преобладание идеалистического мировоззрения, доминирование представлений о глубинной общности религиозных конфессий, отсутствие единства в разных аспектах отношения к религии, свидетельствующее о размытости и эклектичности религиозных представлений в молодежной среде.

В сопоставлении с результатами ранее проведенных исследований сделан вывод о нестандартном понимании религии, религиозных догм и традиционных религиозных конфессиях среди молодежи.

Несомненно, показано, что молодежное понимание религии, религиозности и своей идентичности строятся согласно воспитанию, общественного менталитета. Свобода вероисповедания является одним из важнейших прав человека.

Ключевые слова: конфессия, религия, Казахстан, религиозные организации, светскость, становление, проблемы, молодежь, религиозность, вера, будущее.
\end{abstract}

\author{
T.T. Аймухамбетов ${ }^{1}$, М.М. Нуров ${ }^{2}$, А.Н. Ержанова ${ }^{1}$ \\ ${ }^{\prime}$ Л.Н. Гумилев атындавы Еуразия ұлттық университеті \\ ${ }^{2}$ Абай атындавы Қазақ Ұлттық педагогикалық университеті
}

ЖАСТАРДЫҢ БЕЙРЕСМИ ДІНИ ФАКТОРЫ

Аңдатпа
Мақалада жастардың діни сенімін әлеуметтік-әлеуметтанулық зерттеудің субъективтік-
бағаланатын ұстанымдарынан қорытындылары келтірілген.
Зерттеу материалдары идеалистік дүниетанымның таралуы, діни конфессиялардың терең
қоғамы туралы идеялардың үстемдігі, дінге қатысты әртүрлі аспектілерде бірліктің жоқтығы,
жастар арасында діни идеялардың белгісіздігі мен эклектикасы туралы куәландырады.
Алдыңғы зерттеулердің нәтижелерімен салыстырғанда, жастар арасында дінді, діни
догмалар мен дәстүрлі діни конфессияларды стандартты емес түсіну туралы қорытынды
жасалды.
Діннің, діни сенімнің және олардың сәйкестілігінің жастардың түсінуі тәрбие мен
әлеуметтік мағынада сәйкес жасалды. Дін бостандығы ең маңызды адам құқықтарының бірі
болып табылады.

Түйін сөздер: номинация, дін, Қазақстан, діни ұйымдар, зайырлылық, қалыптасу, 
проблемалар, жастар, діни сенім, сенім, болашақ

\author{
T.T. Aimukhambetov ${ }^{l}$, M.M. Nurov ${ }^{2}$, A.N. Yerzhanova ${ }^{l}$ \\ ${ }^{I}$ L.N. Gumilyov Eurasian national university \\ ${ }^{2}$ Kazakh National Pedagogical University named after Abai
}

\title{
THE FACTOR OF INFORMAL RELIGIOSITY OF YOUTH
}

\begin{abstract}
The article summarizes the results of an empirical sociological study of the religiosity of young people from subjective-evaluative positions.

The materials of the study revealed the prevalence of an idealistic worldview, the dominance of ideas about the deep community of religious denominations, the lack of unity in various aspects of attitude to religion, indicating the vagueness and eclecticism of religious ideas among the youth.

In comparison with the results of previous studies, a conclusion was made about a non-standard understanding of religion, religious dogmas and traditional religious denominations among young people. Undoubtedly, it has been shown that the youth understanding of religion, religiosity and their identity is built according to the upbringing and social mentality. Freedom of religion is one of the most important human rights.
\end{abstract}

Keywords: Denomination, religion, Kazakhstan, religious organizations, secularism, formation, problems, youth, religiosity, faith, future.

\section{1. Введение}

Во многих культурах религия считается частью традиции, и как таковая она рассматривается как неотъемлемая часть общественной жизни. Однако молодые люди вряд ли будут привязаны к традициям и более подвержены различным культурным влияниям как другие социальные институты. Молодежь считает религию практикой пожилых людей. Это связано с тем, что люди воспринимают религию с возрастом и люди, приближающиеся к смерти, ищут сценарий загробной жизни для комфорта и надежды жизни после смерти. Молодые люди знакомятся с религией благодаря своим родителям, но многие из них решают отказаться от своей веры в жизни при или отсрочить на некоторый срок или причисляют себя к верующим той или иной конфессии по каким-либо причинам не зависящих от них.

Актуальность статьи состоит в том, что исследования, проведенные с молодежью и ее отношением к религии, помогают понять место религии в современном обществе и его будущее. Именно молодое поколение находится на переднем крае социальных и культурных изменений. Их участие в религии дает информацию о ее новаторстве, трансформации и адаптации в связи с более широкими культурными и социальными тенденциями, а также о будущем веры и о том, насколько устойчивы практики и верования. Также данная статья будет актуальна из-за простого, но в тоже время выражающего наши реалии выражения, что наша молодежь это наше будущее. В статье рассматривается одна из актуальных тем не только на территории Казахстана, но и во всем мире - проблема понимания религии как отдельного института в среде молодежи и детей, проблема идентичности и причисления молодых людей себя к какой либо религиозной группе, проблема диалога между молодежью, религией и обществом. В статье реализован анализ причин отказа от религии и ухода людей в деструктивные организации, отказа от религии и об идентифицировании молодежи в рамках казахстанской государственности и в сравнении с мировой ситуацией. Автор старался раскрыть особенности казахстанской модели религиозности молодежи и проблем, перечисленных выше, которая особенно при сегодняшнем кризисе должна получить дальнейшее развитие. Сегодня, как ясный день, очевидно противоречие между разными поколениями наносит ущерб не только доверию, но создает проблему глобального развития. Диалог между молодежью и религиями, между об-ществом и религией, между государством и религией все актуальнее.

\section{2. Методика}


Подводя итоги анализа религиозности молодежи Республики Казахстан, автор приводит итоги социологического опроса проведенного в г. Нурсултан. Данный социологический опрос был проведен в формате фокус-группы, респонденты студенты различных колледжей, различных специальностей, возраста от 18 до 20 лет. Он являлся региональным базовым опросом очной формы с качественным методом исследования. Социологический опрос проводился в два этапа.

Актуальность социологического исследования: Актуальность данного исследования обусловлена тем, что в условиях глобализации и роста религиозности привело к необходимости в Республике Казахстан усилить исследующую роль в сфере религии.

Насколько молодежь причисляет себя к таким традиционным конфессиям, как ислам и христианство, насколько изменился уровень религиозности населения, как общество относится к религиозной идентификации в разных социальных аспектах.

В соответствии, с чем для подготовки данной статьи при содействии студентов университетов ЕНУ имени Л.Н. Гумилёва и Туран был проведен социологический опрос, направленное на изучение межконфессиональной ситуации и мнения общества об отношениях к религиозным конфессиям в Республике Казахстан.

Объект исследования: обучающиеся университетов в возрасте от 18 лет до 20 лет.

Предмет исследования: изучение религиозности молодежи и ее идентифицирование со статистикой религиозности среди молодежи

Цель исследования: определить взгляды и видение молодежи на религию, традиционные религиозные конфессии

Для сбора первичной социологической информации в исследовании использовался социологический опрос в форме фокус - группы. Выборка - 150 респондентов.

\section{3. Теоретическая часть}

Современные условия, при которых в Республике Казахстан уделяется большое внимание молодежи, в честь года молодежи, вынуждают государство обратить внимание на разрешение вопросов религиозного возрождения в стране. Протекающие в обществе обновления создали ряд новых, в тоже время сугубо личных проблем. Базовой, среди которых является проблема идентификации новой религиозной картины казахстанского общества. На новую «религиозную» карту Казахстана влияют разного рода факторы - географические, исторические и вызовы современности (интеграция, глобализация), объективные и субъективные аспекты, недостаточная изученность в научно-теоретическом и практическом плане религиозности молодежи страны и др.

На сегодняшний день возросший интерес к религии, стало довольно обыденным и является объективным процессом современного общества, а началом изменения статуса религии и верующих в обществе, создание качественно новой ситуации формирования нашей республике новой модели конфессиональных отношений. Никто не может подвергаться какой-либо дискриминации по мотивам социального происхождения, пола, расы, национальности, языка, отношения к религии и т.д.

Социологическое исследование религии долгое время принимало тезис секуляризации в качестве центральной точки отсчета. В соответствии с этой теорией считается, что значение религии для общества уменьшается по ряду причин: упадок отдельных религиозных верований и практик, растущее ограничение религии в частной сфере и растущая дифференциация между религиозными и другими социальными системами, функции и услуги. Ряд ученых указали на документированное отсутствие существующих социальных исследований не религиозности (например, Bullivant, 2008; Tomlins and Beaman, 2015) [1]. Данный фактор глубоко проблематичен, поскольку угрожает ограничить понимание как не религиозных, так и религиозных взглядов, а также не позволяет заинтересовать общественность и средства массовой информации о наличие данной проблемы, связанной с неправильным пониманием религиозной идентификации индивида. Это особая проблема, если учесть недавний рост числа людей, идентифицирующих себя как нерелигиозных во многих западных контекстах за последние несколько десятилетий. По оценкам Цукермана (2007), в мире насчитывается от 500 
до 750 миллионов человек, которые не верят в Бога. Тем не менее, Томлинс и Биман (2015: 2) [2] сообщают о различных оценках: от 10 процентов населения мира как нерелигиозных (ЦРУ США), 23 процентов как нерелигиозных (Gallup International) [3] и 16 процентов или 1,1 миллиард как нерелигиозный (Pew Research) [4]. Между странами существуют явные различия: Япония, Чешская Республика и Южная Корея часто фигурируют в «10 лучших» списков стран с наибольшим количеством неверующих (Zuckerman, 2007), [5] что подчеркивает наличие отличительных национальных “не религиозных" культур. Числа также различаются для отдельных стран, таких как Великобритания, где Цукерман (2007). По оценкам, по данным социальных опросов, 31-44 процента людей были атеистами, агностиками или неверующими эта цифра намного выше, чем 25 процентов, отметивших «нет религии» в переписи 2011 года. Каковы бы ни были реальные цифры, ясно, что нерелигиозные люди составляют значительную долю населения во всем мире и, следовательно, заслуживают серьезного внимания. Отсутствие исследовательского интереса к основной группе населения, как указано выше, соответствует положению детей и молодежи в социологии до 1990-х годов. До этого периода социологическое исследование детства и юности имело тенденцию включаться в исследования в области образования или семьи с упором на социализацию и формирование молодого человека, то есть как взрослого, когда по сути причисляют молодежь к не существующему члену общества. Научная забота о детях и молодежи как об отдельных лицах обычно оставалась за психологией развития, которая подчеркивала «естественный» биологический и когнитивный прогресс в направлении принятых норм физической и умственной компетентности. Только когда исследователи начали сомневаться в этом отсутствии интереса, начали разрабатываться новые подходы к изучению детства и юности.

Современные исследования детства и юношества в настоящее время зависят от целого ряда факторов, включая «новую» социологию детства, критические исследования молодежи и Конвенцию ООН о правах ребенка 1989 года (UNCRC) [6]. Категории «детство» и «молодость» рассматриваются более критически, как социальные конструкции, значения которых меняются во времени и пространстве. Детство и юность рассматриваются как независимые переменные анализа, пересекающиеся с другими осями социального развития и подразделяются на такие единицы, как семья. Отношения, культура и повседневная жизнь детей и молодежи воспринималась как подразделение семейного. Что в принципе является не правильны, так как самое главное, что дети и молодые люди являются активными социальными агентами, формируя и обсуждая свои социальные миры. Для начала мы хотели бы предоставить вам мировую картину религиозности мира. Взрослые до 40 лет менее склонны к религиозной принадлежности. Возможно, самый простой способ измерить привязанность к религии среди людей всех возрастов - это посмотреть на процент людей, идентифицирующих себя с религиозной группой. Опрос исследовательского центра Реw по всему миру постоянно задает вопрос: «Какова ваша нынешняя религия, если таковая имеется». Респондентам предоставляется список потенциальных ответов для конкретной страны (который обычно включает несколько основных мировых религий, а также «атеист», «агностик», или «ничего особенного»). Для лучшего сравнения хотелось бы предоставит карту, предоставленная этим исследованием [4].

Теперь перейдем к анализу «не религиозности» в нашей стране на основе мировых исследований. Исследования американской службы Гэллапа показывают, что уровень религиозности населения Казахстана (43\%) самый низкий в регионе Азии. В целом, в мире Казахстан занимает по этому показателю место между Словенией и Швейцарией. По данным Министерства по делам религий и гражданского общества РК атеистами или агностиками себя позиционируют $10 \%$ населения. По словам вице-министра по делам религий и гражданского общества Дархана Калетаева сегодня более $14 \%$ казахстанцев позиционируют себя как атеисты или агностики [7].

Но являются ли данные исследования правдоподобны на сто процентов, если мировые данные и данные наших специалистов настолько различны.

Эти исследования позволят сравнить соотношения и обозначить динамику религиозности 
современной казахстанской молодежи, в особенности его отношения к религии. Сравнение результатов проведенных исследований позволяет выделить несколько особенностей: Активный рост религиозности казахстанской молодежи. Но что именно подразумевает этот рост. Ниже будет представлена диаграмма, позволяющая увидеть, как именно идентифицирует себя современная молодежь Казахстана в плане религиозности. Религиозная идентификация молодежи в сравнительном разрезе исследований по-прежнему проявляет динамику роста. Это процесс проявляется в том что, молодые отождествляют себя верующими, однако не участвуют в религиозной жизни [8].

Выяснилось, что всего от 3\% до 17\% молодежи подтвердили свое знание текста молитв. И именно эти $3 \%$ подтверждают, что совершают молитву. От $36 \%$ до $85 \%$ молодежи отмечает, что не знает тексты молитв и $61 \%$ отмечает, что вообще не молится. Наличие поверхностного интереса молодежи к религии. Это предположение подтверждается ответами респондентов на вопрос о том, как вы часто затрагиваете тему религии в разговорах и в общении со своими знакомыми и родственниками, когда большинство респондентов редко затрагивают тему религии в общении со своими знакомыми и родственниками.

\section{4. Практическая часть}

Также хотелось бы привести наше интервью со студентами 1-2 курсов университетов ЕНУ имени Л.Н. Гумилёва и университета Туран.

Интервью, разделенное на две отдельные половины, начинается с обсуждения ее исследования природы веры и того, во что на самом деле верят обычные люди в современном казахстанском обществе. В своем ответе я сосредоточусь на некоторых вопросах, поднятых в отношении веры, расскажу о том, как данная работа может принести пользу исследованиям в области молодежи и образования, и, в частности, объясню, как я нашла подход к изучению веры полезным в моем собственном исследовании из жизни молодых людей, которые считают, что они «не религиозны". Для меня понятие веры часто принималось как должное в изучении религии. Редко мы спрашиваем, что мы имеем в виду, когда говорим о вере?

Академическое изучение религии было «сформировано идеей о том, что религия - это то, во что кто-то верит», и что это равносильно «дискретному, субъективному опыту принятия утверждений относительно происхождения религии»: космос, природа человечества, существование божеств или цель жизни». Такое понимание сохраняется и превалирует в религиозном образовании школ, университетов и коренится в самом менталитета казахстанского общества.

Исследование не только ставит вопросы о том, что мы подразумеваем под верой; она также демонстрирует, как религиозная идентичность часто является сложнее, чем обычная статистика. И оба эти фактора могут иметь большое значение для изучения религии и убеждений в школе, колледже, университете, а также для понимания исследователями, учителями и политиками природы веры в жизни как религиозных, так и нерелигиозных молодых людей.

Первоначальный стимул для интереса к тому, во что на самом деле верят люди, пришел из вышеприведенной статистики, а точнее диаграммы, в которой $83 \%$ респондентов назвали себя

«верующими» [9]. Тем, что несмотря на то, что наше общество становится все более и более светским обществом, казалось озадачивающим, что такая большая часть населения идентифицировала себя таким образом. Я решила более глубоко изучить, что имела в виду молодежь, принявших религиозную идентичность, изучив то, во что они действительно верили.

Представляя себя потенциальным участникам в качестве исследователя социальных наук, а не исследователя религии. Я начала свое интервью, спрашивая людей «во что вы верите?» а не «какая ваша религия?». Только в самом конце интервью я подняла тему религиозной идентичности. Такой подход позволил мне сосредоточиться на вере, не задавая вопросов, касающихся религии. И, сосредоточившись вместо этого на ценностях и значении именно веры, а также на том, что было важно для ее участников. Я смогла узнать гораздо больше о том, как вера функционирует в их жизни, и потенциальной разнице между религией и верой молодых людей.

Изучение «веры» вне рамок «религиозной веры» заставило меня принять аналогичный методологический подход в моем собственном исследовании. Я хотела узнать о людях, местах, 
предметах, видах деятельности и времени - материальных культурах - которые были важны для этих молодых людей, а также понять их убеждения и ценности, их методы построения повествований о значении и влияние семьи, друзей и общества на их жизнь и личность. Я включила вопрос о религии вместе с вопросами, которые были о их личности, и оставила подробное обсуждение причин самоидентификации участников как «не имеющих религии», а также их понимания «религии».

Однако, как обнаружено вопросы о «вере» или «жизни» в целом позволяют участникам более свободно говорить о религии в их жизни. Но, хотя я обнаружила, что религия и религиозные верования играли относительно незначительную роль в жизни некоторых участников, которые, тем не менее, выбрали «верующего» в качестве своей религиозной идентичности. Мое исследование молодых людей, отметивших «не религиозны», указывает на то, что некоторые которые идентифицируют себя таким образом, тем не менее считают религию и религиозные убеждения значимыми в своей жизни.

Исследование дает ценную информацию о некоторых причинах, по которым люди в современном обществе выбирают категорию «верующий» как идентичность при опросе. Для некоторых это является как «социальный маркер», который помогает им чувствовать себя в безопасности в своих сообществах, стирая границу между собой и другими; быть верующим это качество с «рождения», этнической идентичности. Хотя некоторые из них заявляют: «Я не верю ни в какие религии», они называет себя «христианином» или «мусульманином», потому что «в моем свидетельстве о рождении написано, что я «христианин» или «мусульманин». Несмотря на то, что для них «верующий» не имеет большого значения, он не делает, что обычно является «христианским» или «мусульманским», и его понимание верующего - это «тот, кто верит в Бога, Иисуса (Мухаммеда), Библию (Коран) и прочее». Хотя он не верит в эти вещи, его дедушка и бабушка верят, значит и он когда-нибудь возможно будет верить. Такое понимание того, что значит быть верующим, возможно, не удивительно, учитывая, что «термин« вера» ассоциировался с «религией »на протяжении веков».

Исследование дает желанную корректировку для понимания веры, как прежде всего пропозициональной и религиозной, иллюстрируя различные способы функционирования веры во всех наших повседневных жизнях, пересекая традиционные границы между религиозным и светским.

Хотя наши участники интервью отличаются от участников мировых исследований тем, что они идентифицирует себя как «верующие», а не как «не имеющие религии», понимание религии и того, что влечет за собой религиозная идентичность, сходны. Во многих моих интервью стало ясно, что участники сводят «религию» к метафизическим, экзистенциальным или этическим системам убеждений, которые являются либо истинными, либо ложными. Поскольку участники не придерживаются этих убеждений, они ставят флажок «не религиозны». Для некоторых, чтобы идентифицировать себя как верующего, необходимо не только верить всему в этой религии, но и иметь сильную веру в эти убеждения. Одна 16-летняя девочка сказала мне: «Я не думаю, что моя вера в Бога достаточно сильна, чтобы я мог поставить галочку «верующая».... Если бы была какая-то «промежуточная часть», я бы, наверное, поставила галочку. Но чтобы классифицировать то, во что я верю, если выбирать из религии, я бы сказал, что у меня нет религии».

Наши исследовательские интересы в жизни молодых людей, которые сообщают об «отсутствии религии», соответствуют новой области исследований не религиозности и светскости.

\section{5. Заключение}

Благодаря статье мы предоставили рабочее определение «не религиозности» как «в отношении различий к религии среди молодежи, идентифицирующие себя одинаково верующими», что указывает на необходимость рефлексивности не только в отношении конкретных отношений «различия», но и в понимании самой «религии». Это помогло бы продолжить обсуждение ее о том, что «вера» пересекает обычные границы между «религией» и «не религией», делая религию, как она говорит, «подмножеством веры».

Для молодых людей «не религиозными», с которыми я беседовала, «религия» понимается как состоящая из пропозициональных убеждений, которые вытесняются научным знанием. 
Религия требует ограничительных этических убеждений, поведения и вещей, которые ограничивают автономию и личные убеждения. И даже когда религиозная этика достойна восхищения, участники отделяют этику от религии, потому что религия по-прежнему сводится в основном к метафизическим убеждениям.

Хотя было несколько причин, по которым эти молодые люди рассматривали религию и убеждения, таким образом, одно влияние на их понимание явно было связано с тем, чему их учили в школе и основное дома. Стоит уделить большое внимание обучения религиозной грамотности в государственных школах Казахстана. Дополнительные занятия религиоведения является обязательной, и одним из способов, которым школы внедряют религиозную грамотность.

Хотя это может помочь ученикам развить навыки толерантности, этот подход к изучению религии, кажется, укрепляет представление о том, что религия связана с частными, индивидуализированными убеждениями онтологического, эпистемологического и/или морального характера. Он не дает ученикам места для размышлений о том, как «религия» может быть шире, чем согласие с позициональными убеждениями или для дальнейшего изучения природы веры и как она может функционировать во всех наших повседневных жизнях. Более широкое изучение природы веры может показаться одним из способов, с помощью которых молодые люди могут понять религию «вне веры» и начать осознавать роль, которую верования играют во всей нашей жизни, а не рассматривать веру как исключительно пропозициональную и свойственную религии. Поэтому, возможно, следует найти место в учебной программе, чтобы побудить учеников исследовать природу веры как не только маркера религиозной идентичности, но и социальной или реляционной идентичности.

Исследование того, во что на самом деле верят люди, внесло ценный вклад в мое понимание того, как вера функционирует в повседневной жизни простых людей.

Наши исследования, проведенные с 18 - и 20-летними молодым людьми, показывают, что было бы полезно, если бы эти знания делились не только с исследователями религии, но также с педагогами и политиками, чтобы помочь молодежи, изучающая религию и убеждения в школе, колледжах и университетах.

\section{Список использованных источников:}

1. Bullivant, S (2015) Believing to belong: Non-religious belief as a path to inclusion. In: Beaman, LG, Tomlins, S (eds) Atheist identities: Spaces and social contexts. New York: Springer, pp.101-116.

2. Tomlins, S (2015) A common goodness: a snapshot of a Canadian University atheist club, why its members joined, and what that community means to them. In: Beaman, LG, Tomlins, $S$ (eds.) Atheist identities: Spaces and social contexts. New York: Springer, pp.117-136.

3. http://www.gallup.com/poll/108625/More-Religious-Countries-Lower-Suicide-Rates.aspx In More Religious Countries, Lower Suicide Rates. Gallup Polls from 2005 and 2006]

4. Source Pew Research Center: surveys, 2008-2017, "The age gap in religious on around the world"

5. Zuckerman, $P$ (2007) Atheism: Contemporary numbers and patterns. In: Martin, M (ed) The Cambridge companion to Atheism. Cambridge: Cambridge University Press, pp.47-68.

6. Конвенциюо ООН о правах ребенка 1989 года (UNCRC) https://www.un.org/ru/documents/decl_conv/conventions/childcon.shtml

7. Атеизм в Казахстане: жил, живет и будет жить? // https://camonitor.kz/28794-ateizmv-kazahstane-zhil-zhivet-i-budet-zhit.html

8. Курганская В.Д., Дунаев В.Ю., Косиченко А.Г., Подопригора Р.А., Садовская Е.Ю., Чупрынина И.Ю. Научно-исследовательский отчет «Влияние религиозных организаций на молодежь в Казахстане». - Алматы: Центр гуманитарных исследований, 2003. - 158 c.

9. Орынбеков М.С. Генезис религиозности в Казахстане. - 2-е изд., перераб. и доп. Алматы: ИФПР КН МОН РК, 2013. - 204 c.

References:

1. Bullivant, $S$ (2015) Believing to belong: Non-religious belief as a path to inclusion. In: 
Beaman, LG, Tomlins, S (eds) Atheist identities: Spaces and social contexts. New York: Springer, pp.101-116.

2. Tomlins, $S$ (2015) A common goodness: a snapshot of a Canadian University atheist club, why its members joined, and what that community means to them. In: Beaman, LG, Tomlins, S (eds.) Atheist identities: Spaces and social contexts. New York: Springer, pp.117-136.

3. http://www.gallup.com/poll/108625/More-Religious-Countries-Lower-Suicide-Rates.aspx In More Religious Countries, Lower Suicide Rates. Gallup Polls from 2005 and 2006]

4. Source Pew Research Center: surveys, 2008-2017, "The age gap in religious on around the world"

5. Zuckerman, $P$ (2007) Atheism: Contemporary numbers and patterns. In: Martin, $M(e d)$ The Cambridge companion to Atheism. Cambridge: Cambridge University Press, pp.47-68.

6. Konvenciyu OON o pravah rebenka 1989 goda (UNCRC)

https://www.un.org/ru/documents/decl conv/conventions/childcon.shtml

7. Ateizm v Kazahstane: zhil, zhivet i budet zhit'? // https://camonitor.kz/28794-ateizm-vkazahstane-zhil-zhivet-i-budet-zhit.html

8. Kurganskaya V.D., Dunaev V.YU., Kosichenko A.G., Podoprigora R.A., Sadovskaya E.YU., CHuprynina I.YU. Nauchno-issledovatel'skij otchet «Vliyanie religioznyh organizacij na molodezh'v Kazahstane». - Almaty: Centr gumanitarnyh issledovanij, 2003. - 158 s.

9. Orynbekov M.S. Genezis religioznosti v Kazahstane. - 2-e izd., pererab. i dop. - Almaty: IFPR KN MON RK, 2013. - 204 s. 